\title{
The Effects of Motor Cortical Stimulation on the Excitability of Spinal Motoneurons in Man
}

\author{
S. H. MILNER-BROWN, J. P. GIRVIN AND W. F. BROWN
}

SUMMARY: The pyramidal tract and particularly the direct corticomotoneuronal components (DCM) have become increasingly important in the higher primates. Minimal single pulse precentral stimulation in man evokes EMG discharges from the contralateral hand muscles with a latency of 18-21 milliseconds. The excitability changes produced by such cortical stimulation on the upper limb $H$-reflex has been observed to include a short duration early facilitation probably corresponding to the DCM input and a later, longer lasting facilitation mediated by

RÉSUMÉ: La voie pyramidale et particulièrement les composantes cortico-motoneuronales directes (CMD) sont devenues très importantes chez le primates supérieurs. Chez l'homme, une stimulation simple précentrale évoque des décharges EMG des muscles contralatéraux de la main avec une latence de 18-21 millisecondes. Les changements dans l'excitabilité produits par une telle stimulation corticale sur le réflexe $H d u$ membre supérieur, ont été observés. La potentiation du réflexe $H$ dans les membres supérieurs par excitation the same and probably other corticofugal projections. Potentiation of the $H$-reflex in the upper limbs by means of postcentral excitation required much higher single pulse stimulus intensities and the changes in excitability produced on the spinal motoneurons could have been explained by physical extension of the stimulus current to the precentral region. Isometric contraction potentiated the $H$-reflex produced by combinations of precentral cortical and peripheral nerve stimulation but no direct evidence was found to support a possible transcortical basis for the $V_{2}$ stretch reflex.

postcentrale requiert une intensité beaucoup plus haute de stimulus. De plus, les changements dans l'excitabilité produits sur les motoneurones spinaux peuvent être expliqués par une extension physique du courant du stimulus à la région précentrale. Une contraction isométrique potentie le réflexe $H$ produit par des associations de stimulation corticale précentrale et périphérique. Aucune évidence directe n'a été trouvée supportant une base transcorticale possible pour le réflexe d'étirement $V_{2}$.
From the Department of Clinical Neurological Sciences, University Hospital, London, Ontario, Canada.

Reprint requests to Dr. W. F. Brown, Dept. of Clinical Neurol. Sciences, University Hospital, 339 Windermere Rd., London, Ontario, Canada N6G 2K3.

\section{INTRODUCTION}

In the last year, there have been a limited number of opportunities to investigate the cortical control of spinal motoneurons in man by means of direct cortical stimulation. The pyramidal tract (PT) first appears in mammals and the importance of the tract increases in higher primates and man, in particular that part directly connected to motoneurons of distal limb muscles. The pyramidal tract has been found to be responsible for the precision grip and independent digit movement in primates (Tower, 1940; Lawerance, Kuypers, 1968).

New methods have been introduced recently to allow the investigation of the order of recruitment, mechanical properties, (MilnerBrown et al., $1973 \mathrm{a}, \mathrm{b}, \mathrm{c}$ ) and estimation of the number of motor units in human hand muscles (McComas et al., 1971; Brown, 1972 \& 1973; Sica et al., 1974). The results obtained made it relevant to investigate the quantitative importance of the direct cortico-motoneuronal (DCM) input on the electrical and mechanical properties of motor units.

Normally, in man an $\mathrm{H}$ reflex is difficult to demonstrate in the upper limb. However, a combination of voluntary contraction and peripheral nerve stimulation has been shown to produce a clearly defined probable H-wave $\left(V_{1}\right)$ (Paillard, 1959; Hagbarth, 1962; Upton et al., 1971; Gottlieb \& Agarwal, 1973). The descending pathways used to potentiate the H-reflex in voluntary contraction have not been identified. This raised the question of what the quantitative importance of the DCM in particular, and PT inputs in general are to the $\mathrm{H}$ wave potentiation.

Our interest was increased by re- 
cent reports of a possible long loop transcortical stretch reflex $\left(V_{2}\right)$ that may not be either a stretch or transcoritcal reflex in man and other primates. The $V_{2}$ reflex has been observed as an EMG discharge usually produced by an abrupt muscle lengthening or increase in the resistance to contraction with a latency too long to be a spinal reflex and too short to be a reaction time (Marsden et al., 1973). The reflex has been assumed to have a suprasegmental basis and perhaps even to have a transcortical limb. A late discharge of similar latency can be produced by a combination of isometric contraction of a muscle and peripheral nerve stimulation (Upton et al., 1971; Milner-Brown et al., 1973 d, 1975).

Interest in the possibility that $V_{2}$ was indeed a transcortical reflex has been prompted by evidence that spindle primaries do project to the cerebral cortex. In the baboon, however, the projection of spindle primaries is to area $3 \mathrm{~A}$ and does not change PT cell firing (Phillips, et al., 1971). Group II muscle afferent inputs do fire precentral pyramidal tract neurons but the latency is significantly longer than to the postcentral region (Wiesendanger, 1973). It is possible that the late $\left(V_{2}\right)$ response is not mediated primarily via the cortex even though the sensorimotor cortex could alter the amplitude and probability of occurrence of the $V_{2}$ response by changing the excitability and gain of lower pathways. This paper deals with the preliminary resuits on the effect of cortical sitmulation on the $\mathrm{H}$-reflex and questioned suprasegmental reflex $\left(V_{2}\right)$.

\section{METHODS}

The study included 5 patients, 4 explored for epileptic surgery, of whom 1 had a cyst in the occipitoparietal region and 1 a tumor in the shoulder representation pre and postcentral region. Another patient had an arterio-venous malformation in the frontal region. Unfortunately, to date it has not been possible to stimulate the pre and post central regions in the same patient. The results of all 5 patients have been combined in this paper.

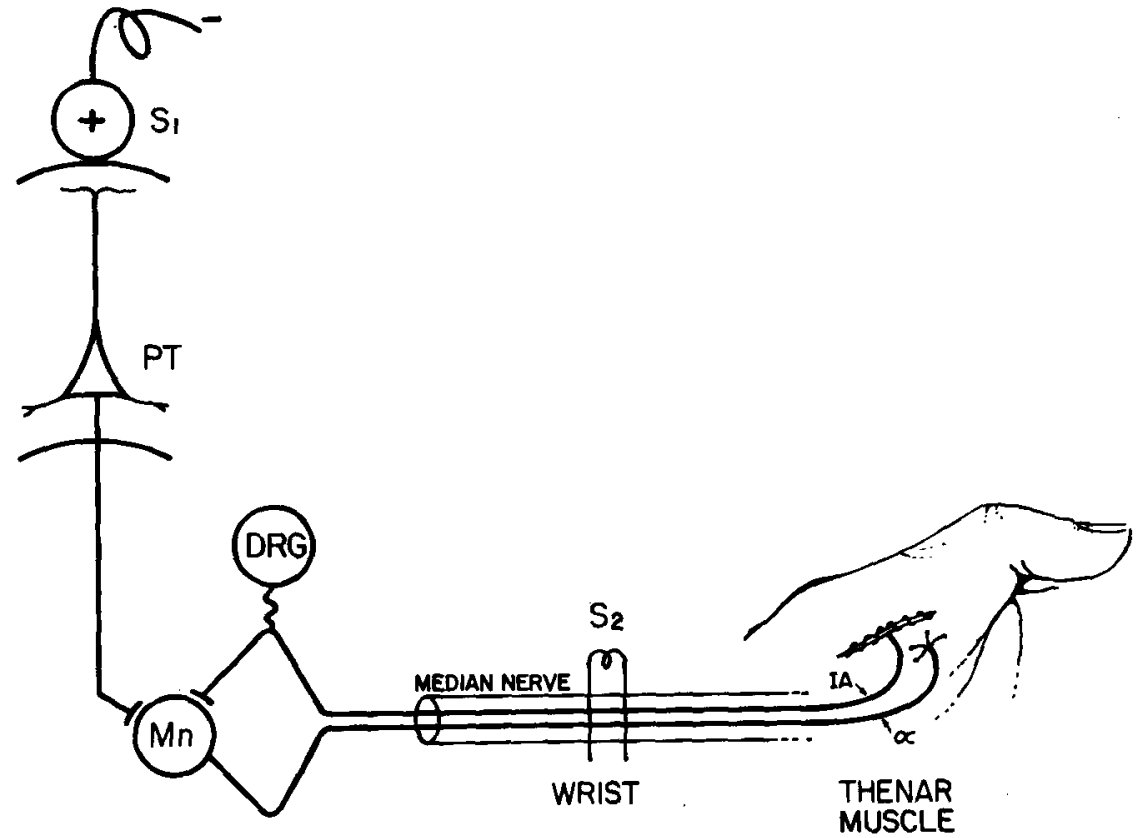

Figure 1-Schematic diagram of experimental set-up $S_{1}$ is the cortical stimulus. The stimulus (surface positive) parameters, 0.1-0.5 msec. duration, $6-12 \mathrm{~mA}, 1 / \mathrm{s}$ were selected so as to preferentially excite pyramidal tract (PT) neurons monosynaptically connected to motoneurons $(\mathrm{Mn})$. $\mathrm{S}_{2}$ - median nerve stimulus at wrist, bipolar pulses, 0.1 msec. duration at $1 / \mathrm{sec}$. DRG - Dorsal Root Ganglion.

In 4 of the patients, the precentral motor cortex was stimulated by means of a ball electrode $4 \mathrm{~mm}$ in diameter held in firm contact to the cortical surface by a spring loaded clamp. Single surface positive, brief ( 0.1 to 0.5 milliseconds) duration pulses $\left(S_{1}\right)$ at less than 1 per second were used to locate the best position for exciting thenar muscle motoneurons and hence to investigate the changes in H-reflex excitability. The best location for the stimulating electrode was determined by locating on the cortical surface the point at which the minimum current produced all or nothing motor unit discharges in the thenar muscles. Such motor unit discharges were not usually visible or palpable in the muscles. A further increase in the stimulus intensity invariably produced a flick movement of the thumb. The best location for such stimulation in each case was within 1 centimeter of the Rolandic fissure.

The parameters of the stimulus were chosen so as to excite as selectively as possible the pyramidal tract neurons directly connected to the motoneurons (Phillips \& Porter, 1962, 1964; Phillips, 1969).
Pyramidal tract neurons in particular the DCM input to motoneurons have been reported to be preferentially excited by brief, weak, anodal, single pulse, cortical surface stimulation in the baboon (Phillips and Porter, 1962, 1964) and to produce monosynaptic EPSPs at times followed by a short latency IPSP. An increase in the intensity of the stimulus not only increased the magnitude of the direct corticospinal volley (D-lateral cord wave) but led to repetitive $\mathrm{PT}$ firing (1-lateral cord waves) (Kernell and Wu Chien-Ping, 1967). Even higher intensity single pulse stimulation probably produced; I. high frequency firing of the pacemaker membrane of the pyramidal tract neuron; II. a mixture of direct and transynaptic excitation of pyramidal tract neurons; III. excitation of other PT cells at a distance by means of physical spread of the stimulating current; and IV. possibly excitation of other intracortical paths and corticofugal cells. Moreover high intensity single pulse stimulation sufficient to produce I waves (Patton and Amassian, 1954) also produces an effect equivalent to high frequency cortical stimulation by producing a 

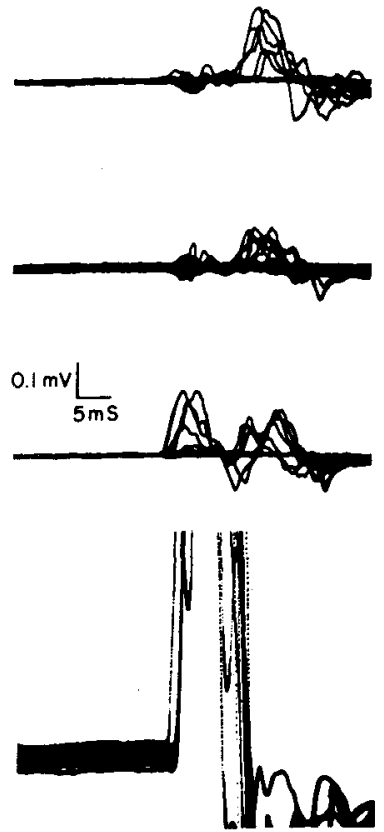

Figure 2-Motor unit discharges in thenar muscles evoked by threshold electrical stimulus to the precentral cortex. The first group activated at minimal threshold stimulus had latencies around $30 \mathrm{msec}$. However a small increase in the stimulus intensity resulted in the appearance of the more characteristic EMG discharge at about $20 \mathrm{msec}$. latency. The $2 \mathrm{EMG}$ group discharges were observed in only one patient.

progressive potentiation in the amplitude of DCM EPSPs, a property of the DCM EPSP not shared by Ia EPSPs. Such a mechanism could bring the DCM EPSP to a level high enough to produce motoneuron firing (Phillips \& Porter, 1962).

Cortical stimulation ( $S_{1}$ in figure 1$)$ of the type used in this investigation in man, probably did produce preferential excitation of PT neurons monosynaptically connected to motoneurons but the higher stimulus intensities required (6-12 milliamperes) could have led to combinations of direct and indirect PT cell excitation and repetitive firing of the PT cells.

Multiple factors could have accounted for the higher current levels needed in man including the obvious possibility that the $S_{1}$ electrode may not, because of limitations in time, have been located at the point of minimum current intensities to evoke hand muscle motor unit discharges. In man, PT neurons with DCM projections are likely to be located in the front wall of the Rolandic fissure and more distant from a surface electrode than comparable neurons in the baboon because of the increased cortical thickness and Rolandic fissure depth in man, factors that could increase that current level necessary to fire the PT cells. Furthermore, unlike the direct intracellular recording from cervical motoneurons in the baboon that made it possible to record minimal DCM EPSPs, the EMG recording in man must of necessity require that the PT EPSPs be large enough to discharge the motoneuron, a requirement that may be dependent on DCM high frequency firing and EPSP potentiation. It was, of course, not possible to exclude stimulation of other corticofugal cells or the effects of PT axon collaterals on other brain stem projections to the motoneurons.

In each patient, the median nerve was stimulated by means of bipolar pulses $0.1 \mathrm{msec}$. in duration located at the wrist $\left(\mathrm{S}_{2}\right)$ (Fig. 1). The size of the maximum compound potential (MCP) produced by the peripheral nerve stimulus was recorded but the excitability curves produced by combining the peripheral nerve and cortical stimuli were obtained by using an $\mathrm{S}_{2}$ stimulus at or close to the motor threshold. At this stimulus intensity level a clearly defined but submaximal antidromic digital sensory potential could be recorded. In each each no $\mathrm{H}$ wave could be recorded using the peripheral nerve stimulus $\left(\mathrm{S}_{2}\right)$ alone.

In one patient it was possible to stimulate the post central region and the best location to produce thenar motor unit discharge was also used to record the somatosensory evoked potential produced by contralateral digital and median nerve stimulation.

\section{RESULTS}

Precentral stimulation at the best position with single pulse cortical stimulation produced all or nothing motor unit discharges in the thenar muscles with minimum latencies of 17 to $22 \mathrm{msec}$. Further increases in the single pulse stimulus intensity reduced the minimum latency by $1-2$ msec. In one individual, minimal threshold stimulation produced the-

\section{MAXIMUM COMPOUND POTENTIALS}

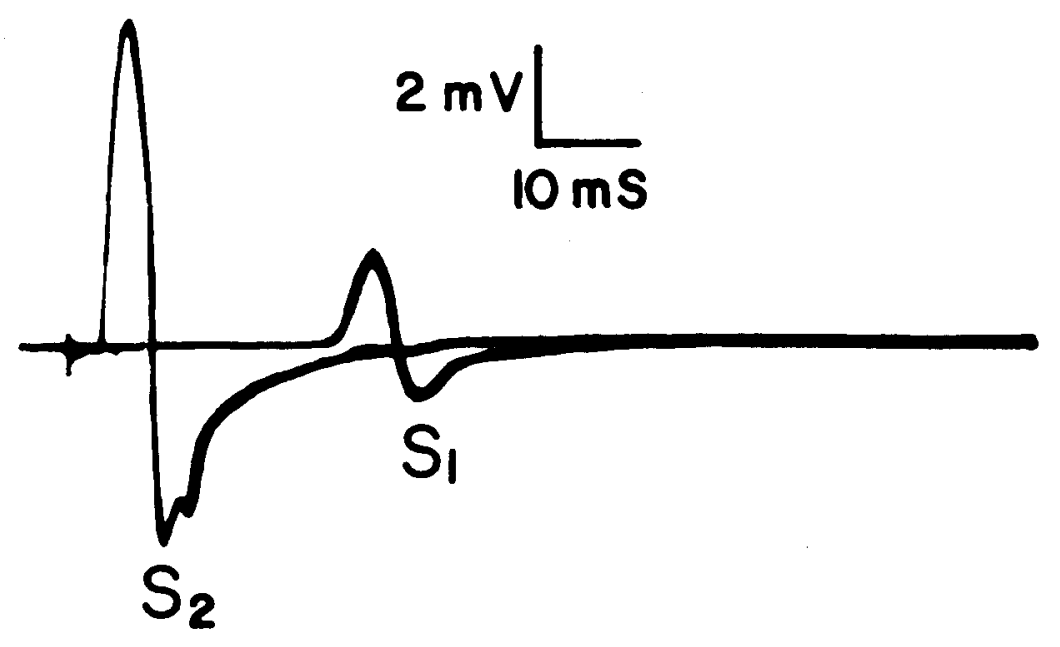

Figure 3-Maximum compound potentials (MCP) recorded from thenar muscles evoked by median nerve stimulation $\left(S_{2}\right)$ and precentral stimulation $\left(S_{1}\right)$. The $S_{1}$ MCP was only $30 \%$ of the S2 MCP. 
CORTICAL STIMULATION AT THRESHOLD

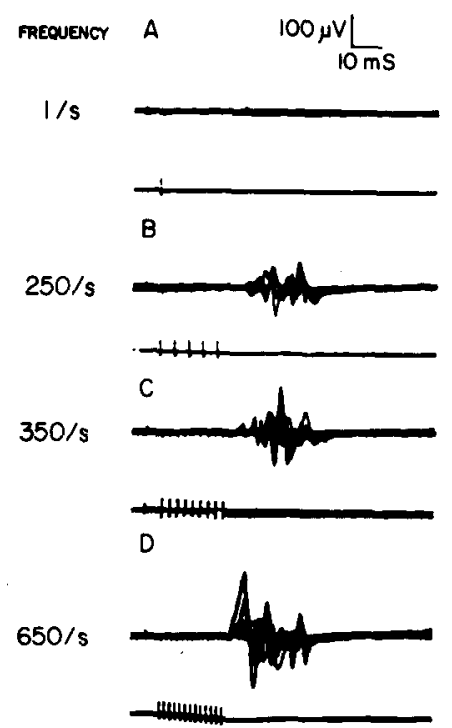

Figure 4-EMG responses recorded from thenar muscles, evoked by threshold cortical stimulation at frequencies $1 / \mathrm{s}, 250 / \mathrm{s}, 350 / \mathrm{s}$ and $650 / \mathrm{s}$, for a total duration of $20 \mathrm{msec}$. There is a progressive increase in the amplitude and a reduction in the latency of the EMG. nar motor unit discharges in 2 groups. The first group activated had latencies around $30 \mathrm{msec}$. but a minimal increase in the stimulus intensity resulted in the appearance of the more characteristic EMG discharge the minimum latency of which was $21.5 \mathrm{msec}$ (Fig. 2). The minimum latency of the maximum compound thenar potential produced by a supramaximal cortical stimulus in this patient was $21 \mathrm{msec}$. In the other four patients including the patient with postcentral stimulation, 2 such distinct groups of motor units with distinctly separate latencies were not observed.

Comparison of the Maximum Compound Potentials (MCP) Evoked by Supramaximal Cortical Stimulation and by Median Nerve Stimulation.

The MCP produced by a single supramaximal cortical stimulus invariably was smaller than the MCP produced by the corresponding supramaximal peripheral nerve stimulus. In fact, in one patient the peak to peak voltage (p-pV) of the MCP produced by the $S_{1}$ pulse was only $10 \%$ of the MCP produced by the $\mathrm{S}_{2}$ stimulation. The largest MCP evoked by a supramaximal Sı single pulse was less than $50 \%$ of the MCP p-pV produced by the $S_{2}$ stimulation despite the fact that the duration of the $S_{1}$ MCP was not longer, an observation that suggested the reduced $p-p$ voltage produced by $S_{1}$ was not primarily a product of temporal dispersion (Fig. 3). Unfortunately there are no reported observation in animals with which to compare the above findings in man. It is of course possible that the obviously reduced amplitude of the cortically evoked MCP could be at least in part the result of temporal dispersion chiefly in the cortico-spinal path because variation in the conduction velocities of motor axons in the peripheral nerve would not have accounted for more than $5-10 \%$ reduction in the $p-p V$ (unpublished results). Clearly also, the median nerve stimulus excites all of the motor axons to the 3 thenar muscles and the first lumbrical muscle. The motor cortex is not organized in terms of peripheral nerves, but includes neurons to other functionally related small hand muscles such as the thumb adductor and first dorsal interosseus muscles probably located nearby flexor, opponens and abductor thenar pyramidal tract neurons. It is not easy,
Figure 5-H-reflex excitability plot of one patient. The ordinate is the amplitude of the $\mathrm{H}$-reflex evoked by combining threshold stimulus to the median nerve $\left(\mathrm{S}_{2}\right)$ and PRECENTRAL region $\left(S_{1}\right)$. $S_{1}$ is fixed at 0 msec.; and the latency of the median nerve stimulus $\left(\mathrm{S}_{2} \mathrm{~L}\right)$ is varied from $-30 \mathrm{msec}$. to $+30 \mathrm{msec}$. at intervals of 2 or $4 \mathrm{msec}$. using a Digitimer. All potentials are averaged values of 20 sweeps.

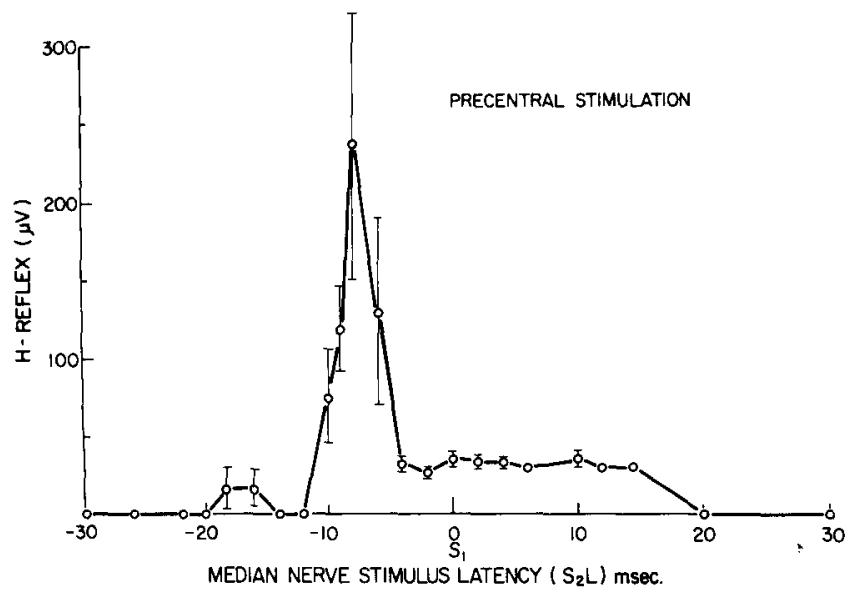

Figure 6-Potentiation of the H-reflex by voluntary contraction. H-reflexes evoked by combining $S_{1}$ and $S_{2}$ at $S_{2} L=-6$ msec. A. muscles relaxed, B. at maximum isometric contraction of thenar muscles. The traces on the extreme left on both figures are part of the $\mathrm{M}$ wave. The stimulus artifacts are not shown. Note the voltage calibration differences in $\mathrm{A}$ and $\mathrm{B}$.

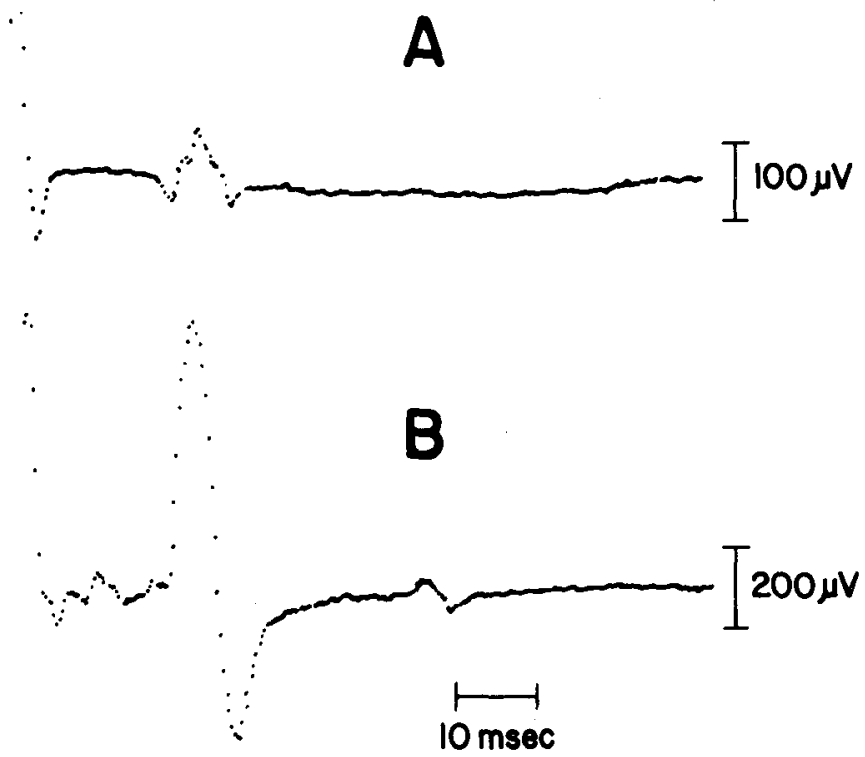




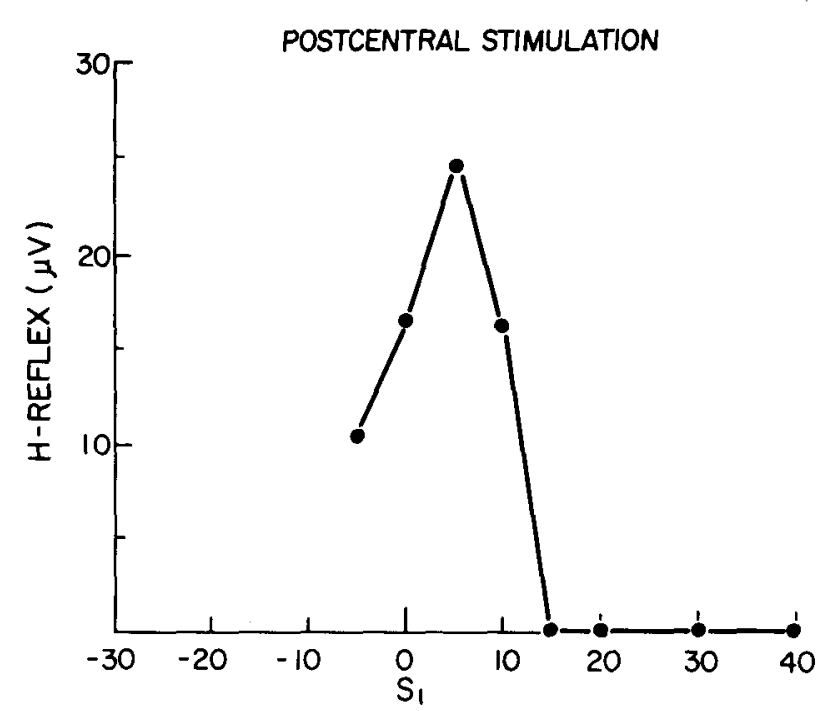

MEDIAN NERVE STIMULUS LATENCY $\left(S_{2} L\right)$ msec.

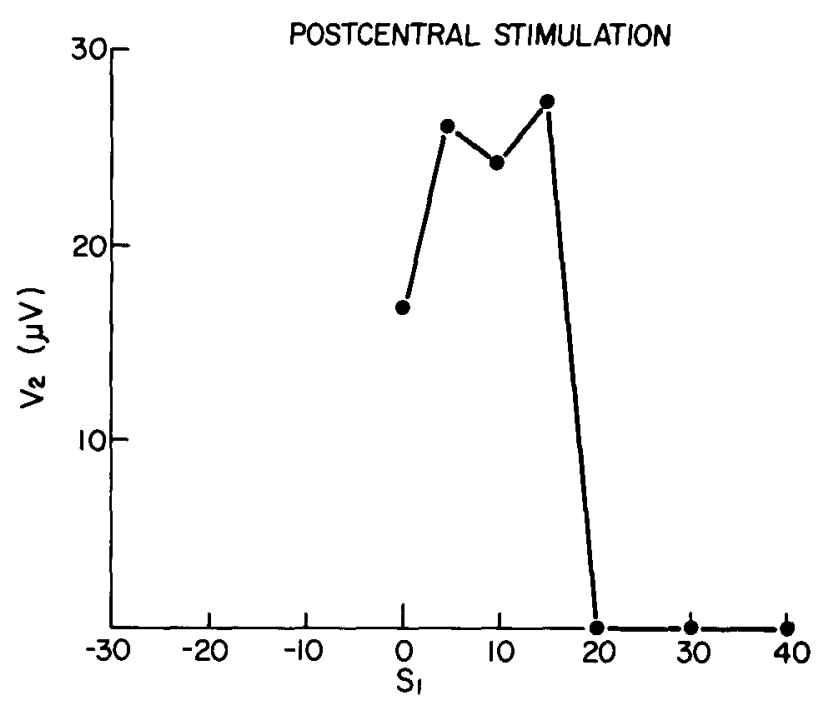

MEDIAN NERVE STIMULUS LATENCY $\left(S_{2} L\right)$ mseC.

Figure 7-H-reflex excitability plot: high intensity $(50 \mathrm{~mA})$ postcentral stimulation. Postcentral stimulus $\left(S_{1}\right)$ was fixed and the median nerve stimulus latency $\left(S_{2} L\right)$ varied from -5 to $+40 \mathrm{msec}$. Investigation was prematurely terminated. The maximum potentiation occurred at $\mathrm{S}_{2} \mathrm{~L}=+.5 \mathrm{msec}$. compared to the precentral maximum at $S_{2} \mathrm{~L}=-8 \mathrm{msec}$. (Fig. 5). The points are averaged values of 20 sweeps.

Figure 8-Excitability plot of the later $\left(\mathrm{V}_{2}\right)$ wave. Ordinate is $\mathrm{V}_{2}$ wave amplitude evoked by a combined high intensity stimulus $\left(S_{1}\right)$ to postcentral region and $S_{2}$, at $S_{2} L=-5$ to +40 msec. Same investigation as in Fig. 7. The points are averaged values of 20 sweeps. therefore, to interpret the obvious difference in amplitude of the MCPs evoked by cortical and peripheral nerve stimulation. The results, however, do raise the question of whether the $\mathrm{CM}$ neurons provide a quantitatively important input to only a fraction of the total hand muscle motoneuron pool.

The Effect of the Frequency of Stimulation on the Latency and Amplitude of the Cortically Evoked EMG Response.

An important and unique property of the DCM input is the property of progressive potentiation of the amplitude of the EPSPs produced by repetitive stimulation (Phillips, 1969). The firing of motoneurons in the baboon and probably man is likely dependent on such a progressive buildup in the size of the DCM EPSP produced by repetitive PT cell firings. In man, high frequency stimulation does increase the amplitude of the evoked EMG response (Fig. 4). In this example, the single pulse $S_{1}$ stimulus was reduced to just below threshold to produce a thenar EMG response. The same stimulus pulse at frequencies of 250,350 , and 650 pulses per second for a total duration of $20 \mathrm{msec}$. produced a progressive increase in the amplitude and a reduction in the latency of the EMG.

\section{The Effect of Cortical Stimulation} on the Monosynaptic Upper Limb H Reflex.

In three patients, it was possible to demonstrate that a combination of near threshold single pulse cortical stimulation and peripheral stimulation produced a potentiated $\mathrm{H}\left(\mathrm{V}_{1}\right)$ response. In one patient, a detailed excitability curve could be obtained by combining the $S_{1}$ and $S_{2}$ pulses (Fig. 5). The duration of the potentiation produced by the cortical input was $28 \mathrm{msec}$. An obvious early maximum potentiation of the $\mathrm{H}$ response was observed that had a time from onset to peak excitability change of 3-4 msec. The maximum excitability change was produced in this case by combining the $S_{1}$ and $S_{2}$ pulses in such a manner that the $S_{1}$ pulse followed the $S_{2}$ pulse by $8 \mathrm{msec}$. In less than $10 \mathrm{msec}$. from the beginning of the early maximum potential, the change in excitability was much reduced and remained almost constant for the next $20 \mathrm{msec}$. or more. The result can be compared with previous studies of the effect of cortical stimulation on the monosynaptic reflex in the upper and lower limb of primates and the cat.

In the cat, cortical stimulation of an intensity sufficient to produce a maximum $D$ wave alone did not potentiate the $\mathrm{H}$ reflex. Only cortical stimulation intense enough to produce $D$ and I waves led to potentiation of the $H$ reflex and no early phase of facilitation was noted of the type clearly identified in the macaque and baboon (Stewart \& Preston, 1967; Preston et al., 1967). In the primate, Stewart and Preston noted an early phase of facilitation followed closely in a few msec. by a phase of inhibition and a late long duration facilitation. The early facilitation has been considered to be the result of the DCM input and to be followed by an early disynaptic inhibition. The phase of inhibition was not observed in the baboon hand muscles (Preston et al., 1967). In man the pattern of excitability changes were basically like the other primate observations that included early and late facilitation phases but one important difference was that 


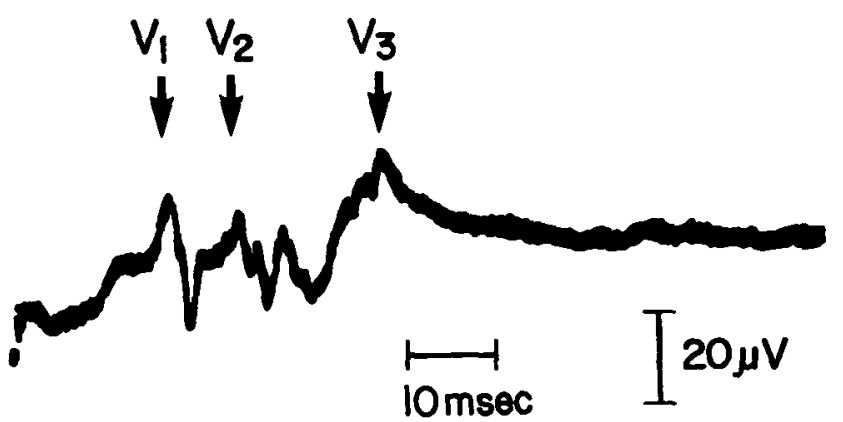

Figure 9-Single EMG response from thenar muscles evoked by combining $S_{1}$ (postcentral) and $S_{2}$ at $S_{2} L=+5$ msec. The latencies to the first peaks are $V_{1}, 35 \mathrm{msec}, V_{2}, 56 \mathrm{msec}$., and $V_{3}, 90$ msec. Data from same investigation as Figs. 7 and 8 .

Figure 10-Schematic representation of waves $\left(\mathrm{V}_{1}, \mathrm{~V}_{2}, \mathrm{~V}_{3}\right)$ recorded in the surface EMG reported by a number of authors, and possible neuronal pathways (arrows) G-S 1964 are 'early' and 'dealyed' waves recorded from gastrocnemius-soleus muscles when nerve stimulation was superimposed on isometric voluntary contraction, by Shimamura et al., 1964. $\mathrm{T} 1971$ are $\mathrm{V}_{1}, \mathrm{~V}_{2}$ waves from thenar muscles reported by Upton et al., 1971; IDI + T 1973 are $V_{1}, V_{2}, V_{3}$ waves recorded from 1st dorsal interosseus and thenar muscles reported by Milner-Brown et al., 1973 and 1975; waves were produced by nerve stimulation and voluntary contraction,

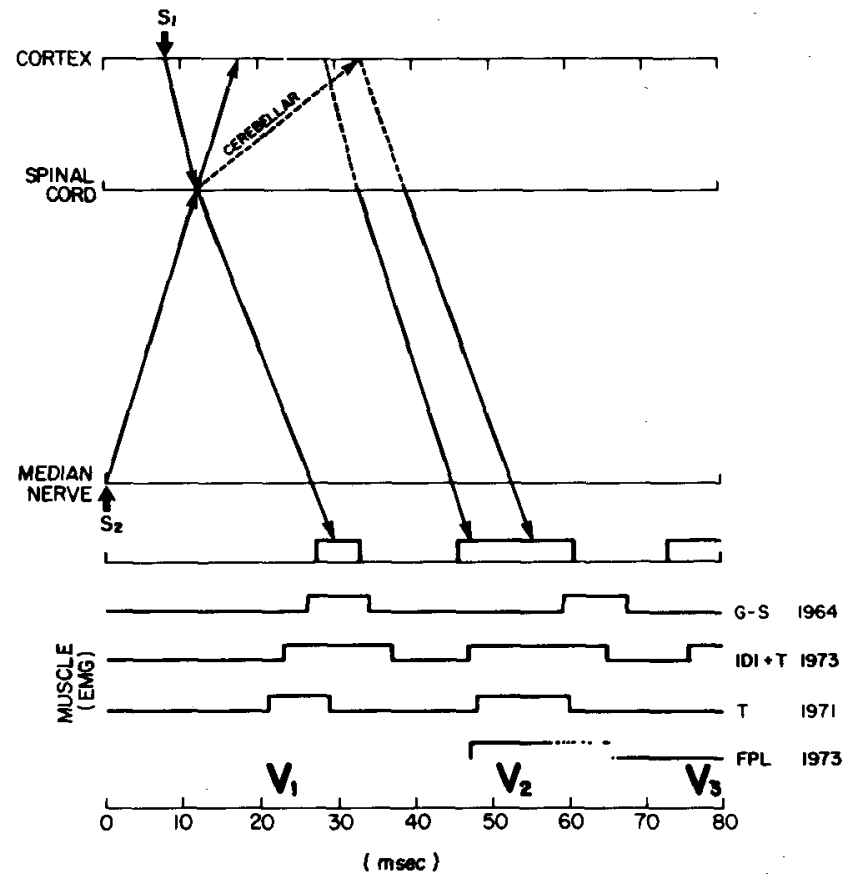

FPL 1973, wave produced by sudden stretch of the flexor pollicis longus (Marsden et al., 1973). Arrows show that a combined $S_{1}$ and $S_{2}$ will produce a $V_{1}(H)$ wave, and a $V_{2}$ wave either via the sensorimotor cortex or via the cerebellum. the initial facilitation was proportionally much greater than the late facilitation unlike the reported findings in lower primates. The abbreviated first phase of facilitation in man could have been the equivalent of the second phase, disynaptic inhibition noted in other primates although there was no way of proving this because the cortical and segmental inputs did not produce EMG responses large enough to recognize an inhibitory phase by a reduction in the EMG.

The late facilitation lasting about 20-30 msec. could have been the result of repetitive PT firing, long duration transmembrane potential changes produced by the single cortico-spinal volley, and other corticofugal inputs mediated by brain stem nuclei of which some are known to have inputs from pyramidal tract axon collaterals.

\section{Voluntary Contraction Potentiation of the VI Response}

Isometric voluntary contraction potentiated the thenar $\mathrm{H}$ response by a factor of 10 times when added to the combined $S_{1}$ and $S_{2}$ stimuli (Fig. 6). The striking potentiation was observed only with isometric contraction of the thenar muscles. Less obvious potentiation was produced by isometric contraction of the long finger flexors and none by biceps contraction.

The Effect of Postcentral Stimulation on the Excitability of the Segemntal $H\left(V_{l}\right)$ Response.

The best location on the postcentral gyrus to evoke a contralateral thenar EMG discharge was less than $1 \mathrm{~cm}$ posterior to the Rolandic fissure. Stimulation at this point produced tingling in the first 3 digits of the contralateral hand and periodically a like sensation in the upper face. Clearly defined somatosensory evoked potentials could be recorded with the electrode in that position by stimulation of the first and second digits but not by stimulation of the third, fourth and fifth digits.

The stimulus current with single pulse stimulation required to evoke an EMG response from the thenar muscles was much higher (40-56 $\mathrm{mA}$ ) compared to precentral stimulation. The latencies to single motor unit responses and the MCP were however comparable to the corresponding latencies produced by precentral stimulation, a finding that suggested that the EMG responses could merely have been the result of the physical spread of current to the precentral regions. The excitability changes (Fig. 7) produced by combining postcentral stimulation and peripheral nerve stimulation however were very different from the corresponding excitability changes in the other 4 patients produced by precentral stimulation. Unfortunately, it was not possible in this patient to stimulate the precentral region in order to directly compare the excitability changes produced by pre and post central stimulation. The maximum potentiations occurred when $S_{1}$ preceded $S_{2}$ by $5 \mathrm{msec}$., unlike the cases of precentral stimulation in which the maximum potentia- 


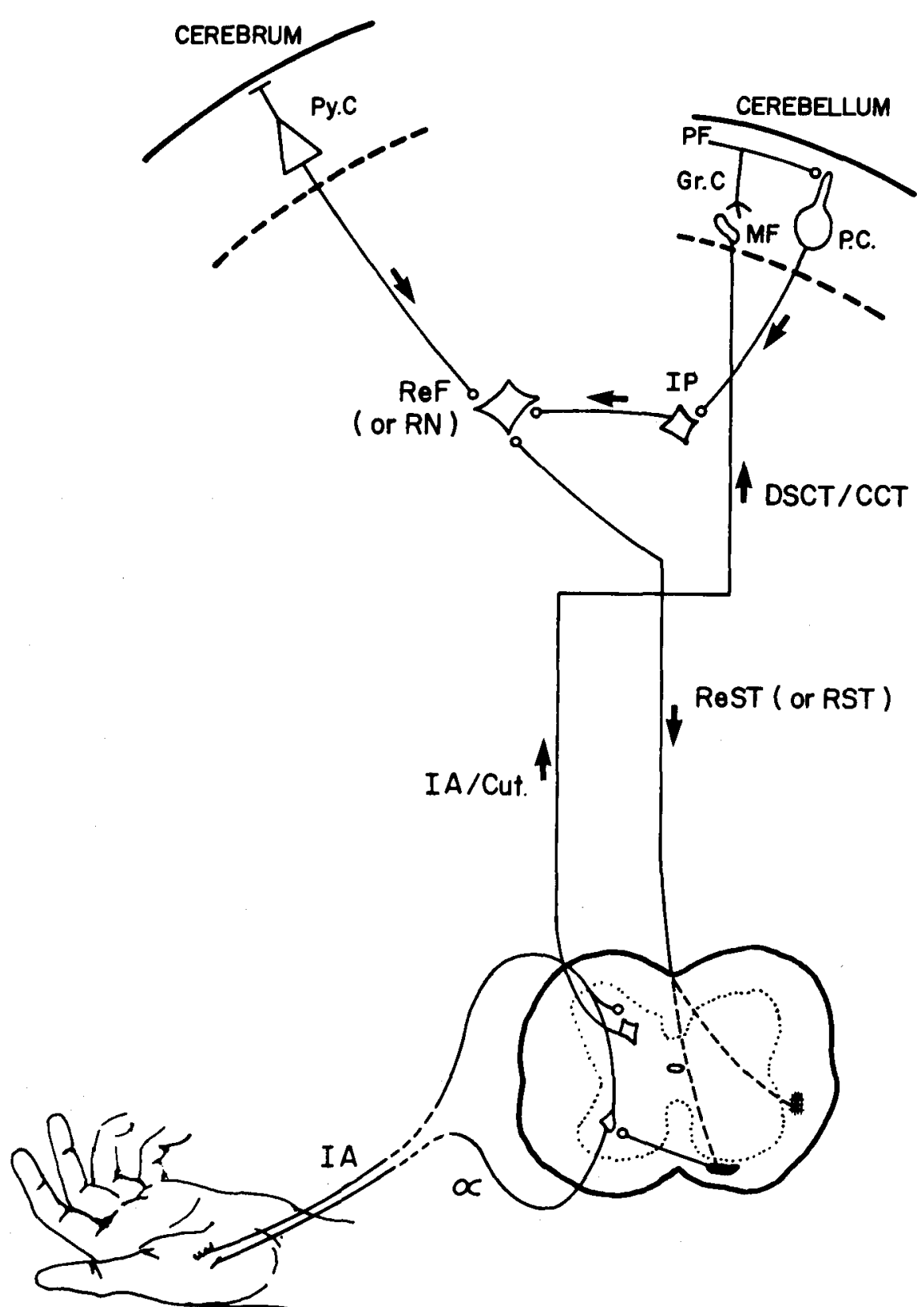

Figure 11-Possible pathways involved in suprasegmental reflexes. DSCT - Direct spino-cerebellar tract, CCT - Cuneocerebellar tract, Gr. C. - Granule cell, Pu Purkinje cell, IP - Interpositus nucleus, ReST - Reticulospinal tract, ReF Reticular formation, RN - Red Nucleus, RST - Rubrospinal tract.

tion occurred when the $S_{1}$ pulse followed the $S_{2}$ pulse by at least $5 \mathrm{msec}$. as in Fig. 5. The fact that postcentral stimulation did not precede the $S_{1}$ pulse by more than $5 \mathrm{msec}$. in this particular investigation made it difficult to exclude the possibility that an earlier period of facilitation like that observed with precentral stimulation could have veen missed. If an earlier period of facilitation had been observed, the change in excitability recorded would have been the equivalent of the second long duration period of facilitation produced by precentral stimulation and have suggested that the excitability changes produced by postcentral stimulation were mediated by the precentral region and probably the result of the simply physical spread of the high intensity post central stimulation to the precentral region.

It was also possible that the post- central potentiation of the $H$ reflex was dependent on stimulation of other corticofugal none PT pathways with longer latencies to the spinal cord or required more temporal stimulation at the cortical brain stem and spinal levels to potentiate the $\mathrm{H}$ reflex. Another possibility was that the potentiation of the $\mathrm{H}$ reflex was primarily mediated by slow conducting $\mathrm{PT}$ axons to account for the longer latency required between the cortical stimulus and segmental $\mathrm{S}_{2}$ input but the fast PT projection alone accounted for the latency from $S_{1}$ to EMG response. The present data in animals and man do not permit a more detailed explanation of the observations produced by post central cortical stimulation.

\section{The Effect of Cutaneous Stimulation on the Excitability of the $\mathrm{H} R e$ - sponse.}

In one subject, stimulation of digits I and II was combined with near threshold cortical single pulse stimulation. The cutaneous input produced no change in the amplitude of the cortical stimulus evoked EMG response up to and including the digital stimulation preceding the cortical $S_{1}$ stimulus by $30 \mathrm{msec}$.

The Effect of Cortical Stimulation on the Later $\left(V_{2}\right)$ Wave.

No later responses were noted by combining minimal precentral and peripheral stimulation even though in each of the four patients a potentiation of the H-reflex was observed. High intensity postcentral stimulation did however potentiate the later waves, and the maximum potentiation was observed when $S_{1}$ preceded $\mathrm{S}_{2}$ by $5-15$ msec. (Fig. 8). When individual responses were stored on an oscilloscope, it was possible to identify three distinct potentials at three different latencies. Fig. 9 shows a typical single evoked response produced by combining $S_{1}$ and $S_{2}$ at $S_{2} L$ $5 \mathrm{msec}$. The range of latencies of the two later waves were $V_{2}, 50-60$ msec., and $V_{3}, 80-95$ msec. One property common to all three waves is that they all increase in amplitude with increasing levels of Volition, and that is how the $\mathrm{V}$ notation originated (Upton et al., 1971). 


\section{DISCUSSION}

The present findings based on intraoperative direct cortical stimulation in man have demonstrated a marked potentiation of the upper limb hand muscle $H$ reflex by $a$ corticospinal, predominantly DCM input. The arguments to support the contention that the cortical stimulus did predominantly select the DCM input have been included in the methods.

The early facilitation was most likely to be the direct result of the DCM input and like the early facilitation reported in other primates. No certain period of disynaptic inhibition was observed. One interesting observation was the predominance of the DCM early facilitation phase versus the late facilitation compared to other primates a finding that probably related to the further development of the pyramidal tract in higher primates and increasing evidence of direct DCM projections especially to distal hand muscles. The DCM projection is likely to be more quantitatively important in man and may point to an even more direct control over the final common pathway by the forebrain.

Precentral stimuli that obviously potentiated the $\mathrm{H}$ reflex did not potentiate a late $V_{2}$ wave and hence did not provide evidence that the DCM input is on the output path of a possible transcortical reflex. This finding is not surprising, however, because such a late EMG discharge has usually been produced by a combination of background facilitation produced by muscle contraction on which have been imposed abrupt displacement or an increased resistance to movement. In the present cases no large background facilitation of the motoneuron pools was provided by muscle contraction. The facilitation of the motoneuron pools at the times necessary to produce a $V_{2}$ response could only be produced by the late excitability changes produced by the peripheral nerve input, late facilitation from the $S_{1}$ input and what must have been a weak input from precentral neurons excited by the incoming somatosensory volley to the pre and post central cortex produced by the $S_{2}$ stimulus. Such an input from peripheral nerve stimulation to the sensorimotor cortex probably included Group I and Group II afferents. Group II spindle afferents and cutaneous afferents have been reported to converge on and to be capa. ble of firing pyramidal tract neurons in the precentral region but the latencies were must longer than the arrival at the post central region (Wiesendanger, 1973).

The shortest possible transcortical reflex time would be approximately $40 \mathrm{msec}$. based on a latency of 18-20 msec. from peripheral nerve afferent input to cortex and an output latency from cortex to hand of $20 \mathrm{msec}$. Fig. 10. The $V_{2}$ wave produced in the flexor pollicis longus and biceps muscles produced by an abrupt lengthening has been reported to be 45 msec. (Marsden et al., 1973) a little less than the $V_{2}$ latency of the thenar muscles $(48-60 \mathrm{msec}$.). The above latencies are at least 5-10 msec. longer than the minimum latency, theoretically possible for such a transcortical reflex. The differences in time could be accounted for by a transcortical reflex dependent on a Group II spindle afferent input to the cortex and the time required intracortically and at the spinal level to bring the PT cells and motoneurons to the firing level.

On the other hand, the $V_{2}$ responses could have been mediated by other pathways, such as the cerebellum and/or brain stem, with the impulses from the cerebral cortex controlling the excitability of this reflex pathway (Fig. 11). Electrical stimuli to a peripheral nerve will excite IA and cutaneous fibers and the afferent pathway could be via the DSCT/CCT to the granule cells of the cerebellum. The efferent pathway could be from the Purkinje cells via the nucleus interpositus (or dentate nucleus) to the reticular formation of the brain stem, where descending volleys from the sensorimotor cortex will provide enough background facilitation to complete the efferent limb through the reticulospinal tract. An alternative efferent limb will be Purkinje, interpositus, (or dentate nucleus) red nucleus, rubrospinal tract, motoneurons. The usual absence of these later waves in reflex studies, can thus be attributed to inadequate facilitation at the brain stem. Milner-Brown, et al (1975) observed that the later waves were much larger among weightlifters, suggesting that specific neuronal pathways can be enhanced by a specific form of physical training. The additional data provided by these studies suggest that the effect of the physical training was probably to improve the efficiency of the background facilitation provided by the cortical input to the brain stem.

The finding that digital nerve stimulation which includes joints and skin afferents but not muscle afferents, did not change the excitability of the motoneurons, suggested that the excitability changes produced by median nerve stimulation were mediated by muscle afferents; most likely group IA primary spindle afferents. In order to make the segmental input more specific, tendon tap, muscle stretch and even muscle vibration could be used instead of stimulation of the median nerve.

The size of the maximum compound potential produced by a supramaximal cortical stimulus was in each case less than $1 / 2$ of that produced by supramaximal median nerve stimulation. Temporal dispersion alone unlikely accounted for such an obvious difference. Possibly the $C M$ input to the cervical motoneurons is quantitatively important to only a proportion of the motoneuron pool and projects primarily unto one functional type of motor unit such as the fast twitch motor units because in man the twitch contraction times are longer and motor unit estimates are less on the hemiplegic side (McComas et al., 1973). To date except for EDC (a uniformly 'fast' muscle), the mechanical properties of motor units excited by the CM path have not been investigated in man or other primates (Phillips, 1969). The data, however, have been too limited to justify much speculation.

This work was supported by the Muscular Dystrophy Association of Canada. S. H. Milner-Brown is MDAC Postdoctoral Fellow. 


\section{DISCUSSION}

Wiesendanger (U.W.O., London) asked whether Group I fibers could potentiate the descending volley, assuming that a transcortical loop was present. Milner-Brown indicated that the study included varying the separation interval between stimulation of the peripheral median nerve and of the cortex by as much as $30 \mathrm{sec}$, and that no late response followed the precentral stimulation. However, high intensity currents applied to the post-central region did evoke a later response with a latency of about $50 \mathrm{msec}$.

Jasper commented that it would be interesting to study inhibition of peripherally evoked H-reflexes when conditioned by cortical stimulation. This would help us understand descending effects on spinal inhibition instead of only excitability.

Phillips drew attention to the fact that muscle twitches were produced by single cortical volleys, perhaps indicating that man has a very dense cortico-motoneuronal connection. He pointed out that this was almost impossible to observe in the baboon. Brown replied that these observations have to be treated cautiously because the intensities of the single shocks were as large as 6-12 ma, as opposed to those used by Phillips with the baboon ( $<4 \mathrm{ma}$ ). Brown added that the high intensity of stimulation could have excited not only PT cells directly, but also could have indirectly excited other corticofugal fibers. From a rough calculation of latencies Phillips wondered whether one had to implicate repetitive firing of cortical neurons to account for the resulting excitability. Brown cautioned that, although the mean time in the four patients with precentral stimulation was $20 \mathrm{msec}$, there was a variation of 2 or 3 msec., and uncertainty about the length of the conducting pathways.

Lawrence (McGill) cautioned against implicating cortical "specificity" in effects on augmentation of the H-reflex of a particular muscle, e.g. flexor pollicis longus. MilnerBrown and Brown agreed, and had not intended such specificity. Firstly, records were made from the thenar muscles collectively, as opposed to a single thenar muscle alone. Secondly, maximum potentiation occurred with contraction of the muscles under the electrode (e.g. thenar muscles) whereas flexion of forearm or proximal limb musculature did not potentiate the response from thumb muscles.

Marshall (Ottawa) questioned whether there was any diminution of the H-reflex by an- tagonistic muscle activation. Brown indicated that although some records suggested that this might have been the case, the experimental design was not such that this question could be answered.

\section{REFERENCES}

BROWN, W. F. (1972). A method for estimating the number of motor unit in thenar muscles and the changes in motor unit count with ageing. Journal of Neurology, Neurosurgery and Psychiatry, 35, 845-852.

BROWN, W. F. (1973). Functional Compensation of Human Motor units in health and Disease. Journal of Neurological Sciences, 20, 199-209.

GOTTLIEB, G. L. and AGARWAL, G. C. (1973). Modulation of postural reflexes by voluntary movement. 1. Modulation of the active limb. Journal of Neurology, Neurosurgery and Psychiatry, 36, 529-539.

HAGBARTH, K. E. (1962). Post-tetanic potentiation of myotatic reflexes in Man. Journal of Neurology, Neurosurgery and Psychiatry, 25, 1-10.

KERNELL, D. and WU CHIEN-PING (1967). Responses of the pyramidal tract to stimulation of the baboon's motor cortex. Journal of Physiology, 191, 653-672.

LAWRENCE, D. G. and KUYPERS, H. G. J. M. (1968). The functional organization of the motor system in the monkey. I. The effects of bilateral pyramidal lesions. Brain 91, 1-14.

MARSDEN, C. G., MERTON, P. A., and MORTON, H. B. (1973). Is the human stretch reflex cortical rather than spinal? The Lancet, April 17, 1973, 759-761.

McCOMAS, A. G., FAWCETT, P. R. W., CAMPBELL, M. J. and SICA, R. E. P. (1971). Electrophysiological estimation of the number of motor units with a human muscle. Journal of Neurology, Neurosurgery and Psychiatry, 36 . 121-131.

McCOMAS, A. J., SICA, R. E. P., UPTON, A. R. M. and AGUILERA, N. (1973). Functional changes in motoneurons of hemiparetic patients. Journal of Neurology, Neurosurgery and Psychiatry, 36, 183-193.

MILNER-BROWN, H. S., STEIN, R. B. and YEMM, R. (1973a). The contractile properties of human motor units during voluntary isometric contractions. Journal of Physiology 228- 285-306.

MILNER-BROWN, H. S., STEIN, R. B. and YEMM, R. (1973b). The orderly recruitment of human motor units during voluntary isometric contractions. Journal of Physiology, 230, 359-370.

MILNER-BROWN, H. S., STEIN, R. B. and YEMM, R. (1973c). Changes in the firing rate of human motor units during linearly changing voluntary contractions. Journal of Physiology, 230 371-390.

MILNER-BROWN, H. S., STEIN, R. B. and LEE, R. G. (1973d). Synchronization of human motor units. Physiology Canada, 4, 193.
MILNER-BROWN, H. S., STEIN, R. B. and LEE, R. G. (1975). Synchronization of human motor units: Possible rate of exercise and supraspinal reflexes. Electroencephalography and Clinical Neurophysiology, 38, 245-254.

PAILLARD, J. (1959). Functional organization of afferent innervation of muscle studied in man by monosynaptic testing. American Journal of Phy siology and Medicine, 38, 239-247.

PATTON, H. D. and AMASSIAN, V. E. (1954). Single- and multiple-unit analysis of cortical stage of pyramidal tract activation. Journal of Neurophysiology, 17, 345-363.

PHILLIPS, C. G. and PORTER, R. (1962). Unifocal and bifocal stimulation of the motor cortex. Journal of Physiology 162, 532-538.

PHILLIPS, C. G. (1969). Motor apparatus of the baboon's hand. Proceedings of the Royal Society (London) B, 173, 141-174.

PHILLIPS, C. G. and PORTER, R. (1964). The pyramidal projection to motoneurons of some muscle groups of the baboon's forelimb in physiology of spinal neurons. - Progress in Brain Research. Ed. Eccles and Shade. 12, 222-242.

PHILLIPS, C. G., POWELL, T. P. S. and WIESENDANGER, M. (1971). Projection from low-threshold muscle afferents of hand forearm to area 3a of baboon's cortex. Journal of Physiology, 217, 419-446.

PRESTON, J. B., SHENDE, M. C., and UEMURA, K. (1967). The motor cortex - Pyramidal System: Patterns of facilitation and inhibition of motoneurons innervating limb musculature of cat and baboon and their possible adaptive significance. In Neurophysiological basis of normal and abnormal motor activities. Ed. Purpura, D. P. and Yahr, M. D., p. 61-74.

SHIMAMURA, M., MORI, S., MATSUSHIMA, $\mathbf{S}$. and FUJIMORI, B. (1964). On the spino-bulbospinal reflex in dogs, monkeys and man. Japanese Journal of Physiology 14, 411-421.

SICA, R. E. P., McCOMAS, A. J., UPTON, A. R. M. and LONGMIRE, D. (1974). Motor unit estimation in small muscles of the hand. Journal of Neurology, Neurosurgery and Psychiatry, 37, 55-67.

STEWART, D. H. and PRESTON, J. B. (1967). Functional coupling between the pyramidal tract and segmental motoneurons in cat and primate. Journal of Neurophysiology, 30, 453-465.

TOWER, S. (1940). Pyramid lesions in the monkey. Brain 63, 36-90.

UPTON, A. R. M., McCOMAS, A. J. and SICA, R. E. P. (1971). Potentiation of 'late' responses evoked in muscles during effort. Journal of Neurology, Neurosurgery and Psychiatry; 34 699-711.

WIESENDANGER, M. (1973). Input from muscle and cutaneous nerves of the hand and forearm to neurons of the precentral gyrus of the baboon and monkey. Journal of Physiology, 228, 203-219. 